\title{
Nonalcoholic fatty liver disease: A clinical approach and review
}

\author{
Maitreyi Raman MD, Johane Allard MD
}

\begin{abstract}
M Raman, J Allard. Nonalcoholic fatty liver disease: A clinical approach and review. Can J Gastroenterol 2006;20(5):345349.

Nonalcoholic fatty liver disease (NAFLD) is the most common cause of incidental elevation of liver enzymes in North America and Europe. Risk factors for NAFLD include body mass index of $25 \mathrm{~kg} / \mathrm{m}^{2}$ or greater, central obesity and diabetes mellitus. The spectrum of disease is variable, ranging from simple steatosis with benign prognosis, to nonalcoholic steatohepatitis and cirrhosis, conferring increase in morbidity and mortality. The primary abnormality or 'first hit' in patients with NAFLD is insulin resistance leading to hepatic steatosis. The second hit involves multiple proinflammatory cytokines resulting in nonalcoholic steatohepatitis. Treatment is aimed at aggressive risk factor control and weight loss. Currently, there are no pharmacological agents recommended in the treatment of NAFLD, although preliminary studies suggest promising agents in the future.
\end{abstract}

Key Words: Insulin resistance; Nonalcoholic fatty liver disease; Obesity
Tudwig et al (1) described the term nonalcoholic steatoLhepatitis (NASH) in 1980 to describe biopsy findings in patients with steatohepatitis in the absence of significant alcohol intake. It is quite difficult to delineate at what threshold steatohepatitis becomes alcohol-related. Traditionally a maximum of $20 \mathrm{~g} /$ day to $40 \mathrm{~g} /$ day of alcohol in men and $20 \mathrm{~g} /$ day of alcohol in women represent the upper limit of alcohol intake to maintain the diagnosis of nonalcoholic fatty liver disease (NAFLD). The spectrum of NAFLD is broad, ranging from simple steatosis to NASH. NAFLD remains a pathological diagnosis requiring a minimum of $5 \%$ steatosis on the liver biopsy to confer the diagnosis.

\section{EPIDEMIOLOGY AND RISK FACTORS}

The conventional risk factors for the development of primary NAFLD include type II diabetes, insulin resistance, hyperlipidemia and obesity (2). NAFLD typically affects $50 \%$ of diabetics and $76 \%$ of obese patients $(3,4)$, and is the most common of all liver diseases. However, the prevalence of $\mathrm{NASH}$ is substantially less, affecting $18.5 \%$ of obese patients. Other traditional risk factors include hyperuricemia, central obesity defined as waist circumference greater than $100 \mathrm{~cm}$ in males and greater than $88 \mathrm{~cm}$ in females, and hypertension. Secondary causes of NAFLD include nutrition-related complications, such as total parenteral nutrition, rapid weight loss,

\section{La stéatose hépatique non alcoolique : Une démarche et une analyse cliniques}

\begin{abstract}
La stéatose hépatique non alcoolique (SHNA) est la principale cause d'élévation auxiliaire des enzymes hépatiques en Amérique du Nord et en Europe. Les facteurs de risque de SHNA incluent un indice de masse corporelle de $25 \mathrm{~kg} / \mathrm{m}^{2}$ ou une obésité tronculaire encore plus importante accompagnée d'un diabète sucré. Le spectre de la maladie est variable, d'une stéatose simple au pronostic bénin à une stéatohépatite non alcoolique associée à une cirrhose qui augmente la morbidité et la mortalité. L'anomalie primaire, ou première occurrence, chez les patients atteints d'une SHNA est une insulinorésistance provoquant une stéatohépatite. La deuxième occurrence touche des cytokines proinflammatoires multiples entraînant une stéatohépatite non alcoolique. Le traitement vise le contrôle agressif des facteurs de risque et la perte de poids. Pour l'instant, aucun agent pharmacologique n'est recommandé pour traiter la SHNA, mais des études préliminaires sont prometteuses à cet égard.
\end{abstract}

and intestinal jejunoileal bypass surgery (Table 1). Certain drugs are associated with NAFLD (Table 2). Metabolic syndromes and pregnancy-related fatty liver diseases are also some of the secondary causes of NAFLD. Patients with normal body mass index (BMI) may develop NAFLD even in the absence of traditional risk factors. It is thought that the primary abnormality may be occult insulin resistance or central adiposity (5). The natural history of NAFLD still remains poorly defined. Mortality among NAFLD patients approaches $13 \%$, which is greater than age- and sex-matched controls (6). Because these patients often have features of the metabolic syndrome, they are at high risk for cardiac-related death. Hence, both ischemic heart disease and malignancy are the leading causes of death in patients with NAFLD. However, liver disease is the third most common cause of mortality in this population, accounting for $13 \%$ of all deaths. This is significantly different than patients without NAFLD, in whom liver-related causes of mortality account for less than $1 \%$ of all deaths (6). Clinical predictors of more advanced disease include people with diabetes, hypertriglyceridemia (7) and those older than 40 years of age.

\section{DIAGNOSIS}

Most patients with NAFLD are asymptomatic or suffer from nonspecific symptoms and signs such as fatigue, malaise or right upper quadrant pain. In most cases, the diagnosis is suspected in

University Health Network, Toronto General Hospital, Toronto, Ontario

Correspondence: Dr Maitreyi Raman, Toronto General Hospital, 585 University Avenue, 9N-973, Toronto, Ontario M5G 2 C4.

Telephone 416-340-5159, fax 416-348-0065, e-mail maitreyi.raman@uhn.on.ca

Received for publication December 20, 2005. Accepted December 20, 2005 
TABLE 1

Disorders associated with steatosis and nonalcoholic steatohepatitis

\begin{tabular}{ll}
\hline Acquired & \\
\hline Diabetes mellitus & Inflammatory bowel disease \\
Extreme malnutrition & Obesity \\
Hyperlipidemia & Total parenteral nutrition \\
Jejunoileal bypass & Biliopancreatic diversion \\
Extensive small bowel resection & Gastroplasty for morbid obesity \\
Partial lipodystrophy & Jejunal diverticulosis with \\
& bacterial overgrowth \\
Inborn errors of metabolism & \\
\hline Abetalipoproteinemia & Familial hepatosteatosis \\
Galactosemia & Glycogen storage disease \\
Hereditary fructose intolerance & Homocystinuria \\
Systemic carnitine deficiency & Tyrosinemia \\
Weber-Christian syndrome & Wilson's disease \\
\hline
\end{tabular}

TABLE 2

Drugs associated with nonalcoholic fatty liver disease

\begin{tabular}{llll}
\hline Cytotoxic & Antibiotics & Other drugs & Nucleoside analogues \\
\hline L-asparaginase & Azaserine & Amiodarone & Didanosine \\
Azauridine & Puromycin & Dichloroethylene & Stavudine \\
Methotrexate & Bleomycin & Ethyl bromide & Fialuridine \\
& & Tetracycline & Hydrazine \\
& & Isoniazid & Zidovudine \\
& Diltiazem & \\
& Coumadin & \\
& Estrogens & \\
& & Glucocorticoids & \\
& & Tamoxifen & \\
& & Nifedipine & \\
& & Chloroquine &
\end{tabular}

the context of the appropriate risk factor profile and incidental elevation of transaminases. Levels of aspartate aminotransferase and alanine aminotransferase are modestly elevated, although the ratio of aspartate aminotransferase to alanine aminotransferase is less than one, distinguishing NAFLD patients from those with alcohol-induced liver disease (8).The degree of elevation of transaminases does not reflect the underlying severity of the disease. The diagnosis of NAFLD can be suspected on the basis of radiological imaging such as ultrasound or magnetic resonance imaging. However, the sensitivity of these modalities is low and often there is a significant degree of interobserver variability. A minimum of $30 \%$ of hepatocytes needs to be infiltrated by steatosis for the imaging techniques to detect fatty liver (9). Currently, the only method of distinguishing simple steatosis from NASH is the liver biopsy. Brunt et al (10) proposed a grading and staging system for NASH. Grade 1 reveals mild steatosis, predominantly macrovesicular with minimal ballooning of hepatocytes and minimal inflammation. Grade 2 shows moderate steatosis, usually mixed macrovesicular and microvesicular with ballooning present in zone 3 hepatocytes, and some lobular inflammation. Grade 3 shows all the features of grade 2 plus the additional requirement of portal

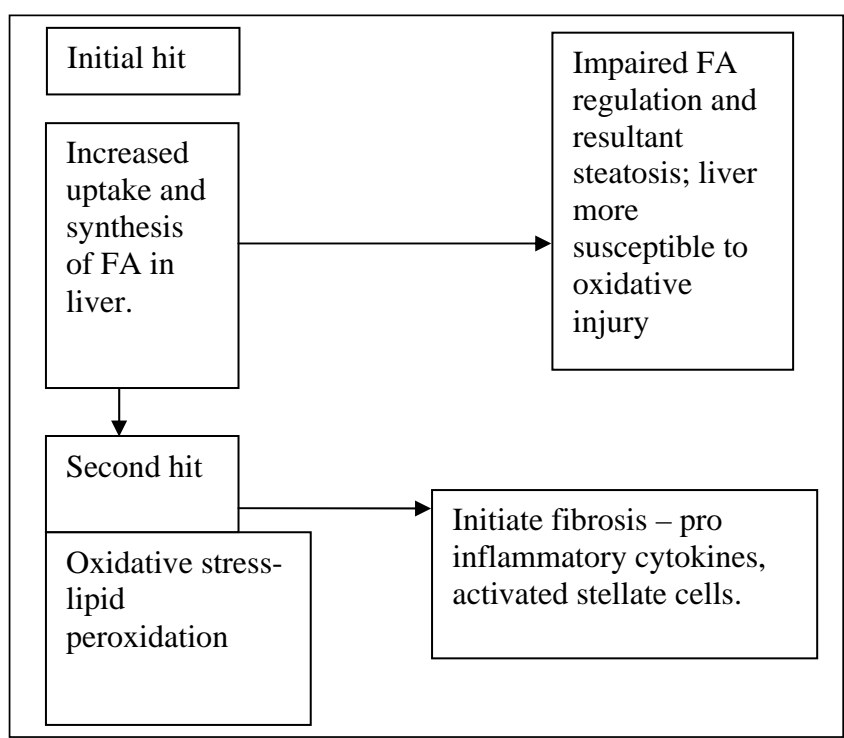

Figure 1) Two-hit hypothesis. FA Fatty acids

inflammation. Staging requires the presence of Masson trichrome stain. Stage 1 reveals zone 3 perivenular, perisinusoidal fibrosis, either focal or extensive. Stage 2 requires the features of stage 1, plus focal or extensive portal fibrosis. Stage 3, shows bridging fibrosis and stage 4 reveals cirrhosis with or without perisinusoidal fibrosis.

\section{PATHOGENESIS}

The progression from simple steatosis to steatohepatitis, fibrosis and cirrhosis is thought to be a two-hit hypothesis (Figure 1).

\section{First hit}

The first hit results in fat accumulation within the liver parenchyma. This occurs in abnormalities during uptake, synthesis and secretion of lipids resulting primarily from insulin resistance, which is quite common in patients with NAFLD (11). Insulin resistance is often a primary abnormality in patients with NAFLD. There is often a genetic predisposition to insulin resistance, even in the absence of frank diabetes. Twenty per cent of the nondiabetic population may exhibit insulin resistance. Patients that exhibit more pronounced levels of insulin resistance exhibit a greater degree of steatosis (12). Central adiposity may contribute to the flow of excess free fatty acids (FFAs) to the liver by providing a direct route through the portal vein (13). Patients with NAFLD often have risk factors such as type II diabetes, hyperlipidemia, hypertension and obesity, which are part of the insulin resistance syndrome. Hyperinsulinemia promotes lipolysis in the adipocyte, resulting in increased FFAs delivered to the liver. In the hepatocyte, FFAs stimulate synthesis of more FFAs and inhibit oxidation of FFAs (14). Insulin sensitivity is also influenced by peptide mediators, otherwise known as adipocytokines, such as tumour necrosis factoralpha (TNF- $\alpha$ ), leptin and adiponectin and although the mechanisms by which this occurs remain largely unknown, theories are suggested. TNF- $\alpha$ influences steatosis by stimulating the release of FFAs from adipocytes into the liver. TNF- $\alpha$ may directly induce apoptosis of hepatocytes promoting activation of hepatic stellate cells, stimulating fibrosis (15). Leptin potentially may stimulate platelet-derived 
growth factor, ultimately leading to hepatic stellate cell proliferation resulting in fibrosis (16). Adiponectin may have a protective role against fatty liver. Recently it was shown that adiponectin levels were significantly reduced in patients with NAFLD compared with controls resulting in an inverse relationship between insulin resistance and adiponectin levels (17). This observation may result in a future therapeutic role in the pharmacological management of NAFLD.

\section{Second hit}

The second hit is hepatocellular injury that results from oxidative stress, lipid peroxidation and direct cellular toxicity from FFAs (18). Multiple mechanisms regarding hepatocyte injury have been proposed:

1. Increased expression of cytochrome P450 isoform CYP2E1 has been shown to occur in patients with NASH. CYP2E1 is a pro-oxidant, resulting in increased production of reactive oxygen species, capable of peroxidizing cell membranes.

2. Increased insulin leads to peripheral lipolysis resulting in excess fatty acids which catalyzes lipid peroxisomes. Peroxisomes are involved in the oxidation process of fatty acids. Oxidation, along with binding and export of fatty acids, is the primary method of protecting the liver from subsequent damage.

3. The peroxisome proliferators activated receptor-alpha $($ PPAR $-\alpha)$ is responsible for regulating the esterification and export of fatty acids in very low density lipoprotein, in the binding of fatty acids and in mitochondrial and peroxisomal oxidation. Reduced expression of PPAR- $\alpha$ may have an important role in the pathogenesis of NASH (19).

4. Mitochondrial abnormalities have been described in patients with NASH, but not in those with simple steatosis. These mitochondrial abnormalities lead to increased mitochondrial fatty acids beta-oxidation, eventually resulting in free radical formation hepatocyte injury and steatohepatitis. Patients who are insulin resistant but do not have mitochondrial abnormalities may develop fatty liver; however, generally they do not progress to steatohepatitis (20).

\section{MANAGEMENT}

\section{Conservative management}

Currently, management is aimed at lifestyle modification, primarily targeting weight loss achieved through dietary modification and exercise. Additionally, treatment of all other aspects of the metabolic syndrome must be instituted. Weight loss and exercise both improve insulin resistance (21), which theoretically should improve steatosis. No randomized controlled study has been run to evaluate whether histological regression occurs in patients with steatohepatitis or fibrosis after weight loss, although case reports and open-label studies suggest improvement. Weight loss should not exceed more than $1 \mathrm{~kg}$ per week, because rapid weight loss can exacerbate steatosis. Similarly very low calorie diets that give less than $500 \mathrm{kcal} /$ day and jejunoileal bypass surgery should be avoided as a method of weight loss, due to the risk of worsening fibrosis. The recommended target for weight loss is $10 \%$ of a person's body weight over a six-month period (22).
Multiple popular diets exist as methods of weight loss. Some diets are founded on years of medical experience, while others have deviated substantially from mainstream medical advice. The Weight Watchers program is one of the traditional models, restricting portion sizes and total calories consumed. Other popular diets include carbohydrate restriction without fat restriction (Atkins diet), macronutrient and glycemic load modification (Zone diet) and fat restriction (Ornish diet). In obese patients with BMI greater than $35 \mathrm{~kg} / \mathrm{m}^{2}$, no significant differences were found regarding amount of weight lost at the end of one year (23). Reduction of cardiovascular risk factors correlated with amount of weight loss. Weight loss of $3 \mathrm{~kg}$ to $6 \mathrm{~kg}$ over one year was achieved regardless of type of diet followed. Currently, no data exist regarding various types of diets in patients with NASH.

\section{Weight loss medications}

Weight loss-inducing medications are not routinely used in the treatment of NAFLD, and have not been studied in randomized clinical trials. One case series suggested that orlistat in patients with NASH was safe, and showed significant histological improvement in both degree of steatohepatitis and fibrosis after six to 12 months of therapy (24). Orlistat is a reversible inhibitor of gastric and pancreatic lipase, and is one of two agents that have been approved for the management of obesity. This medication forms a covalent bond with the active serine residue of gastric and pancreatic lipase in the stomach and small bowel, blocking the digestion and absorption of dietary triglycerides. Orlistat in combination with a controlled energy diet, rather than diet alone, significantly increased weight loss in obese adults after one year of therapy (25).

The second approved drug in the management of obesity is sibutramine. Sibutramine was evaluated in one nonrandomized study in patients with NASH (26). Sibutramine in combination with a low calorie diet-induced weight loss improved insulin resistance and transaminases, as shown by ultrasonographic regression in fatty liver, compared with diet alone. It is a noradrenaline-serotonin reuptake inhibitor and produces weight loss by a dual mechanism: reduction of food intake and increase in energy expenditure. Average weight loss is in the range of $5 \%$ to $8 \%$ from baseline. Recently, rimonabant, a selective cannabinoid-1 receptor blocker, has been shown to improve cardiovascular risk factor profile and reduce body weight (27). Over 1000 overweight patients with BMIs between $27 \mathrm{~kg} / \mathrm{m}^{2}$ and $40 \mathrm{~kg} / \mathrm{m}^{2}$ participated in this study examining the effects of rimonabant and metabolic risk factors. Mean weight loss was $6.6 \mathrm{~kg}$ over 12 months at a dose of $20 \mathrm{mg}$. Additionally, waist circumference was reduced, plasma high density lipoprotein levels increased, and plasma adiponectin levels were significantly higher in patients receiving rimonabant compared with placebo. This medication, and other weightreducing agents, may represent future therapeutic options for the pharmacological treatment of obese patients with NASH.

Certainly, diet should be combined with exercise to initiate and maintain weight loss. Exercise will enhance calorie deficit necessary for weight loss. A minimum of 30 min of moderate sustained activity five days per week is necessary to gain health benefits from exercise (28). Any fitness regimen should include a balance of aerobic exercise, strength and flexibility training. 
TABLE 3

Randomized controlled trials (RCT) evaluating pharmacological therapy in patients with nonalcoholic steatohepatitis (NASH) plus pilot studies showing improvement in biochemical and histological parameters in patients with NASH

\begin{tabular}{|c|c|c|c|c|c|c|}
\hline Therapy & Duration months & Type of study & Liver enzymes & Inflammation & Fibrosis & Reference \\
\hline Metformin & 6 & RCT & - & - & - & Uygun et al (35) \\
\hline Ursodeoxycholic acid & 24 & $\mathrm{RCT}$ & - & - & - & Lindor et al (36) \\
\hline Vitamins $\mathrm{E}$ and $\mathrm{C}$ & 6 & $\mathrm{RCT}$ & - & - & $\uparrow$ & Harrison et al (37) \\
\hline Rosiglitazone & 12 & Open-label & $\uparrow$ & $\uparrow$ & $\uparrow$ & Neuschwander-Tetri et al (30) \\
\hline Pioglitazone & 12 & Open-label & $\uparrow$ & $\uparrow$ & $\uparrow$ & Promrat et al (31) \\
\hline Betaine & 12 & Open-label & $\uparrow$ & $\uparrow$ & $\uparrow$ & Abdelmalek et al (38) \\
\hline Orlistat & 24 & Open-label & $\uparrow$ & $\uparrow$ & $\uparrow$ & Harrison et al (24) \\
\hline
\end{tabular}

\section{Pharmacotherapy evaluated in the treatment of NAFLD}

Currently, there are no approved pharmacological options for the treatment of NAFLD. Only three randomized controlled trials have been conducted to evaluate the efficacy of medical treatment in NAFLD (Table 3). The agents studied include antioxidants with vitamins $\mathrm{E}$ and $\mathrm{C}$ in combination, ursodeoxycholic acid and metformin. Although there was improvement in liver enzymes and steatosis in the trial evaluating metformin, there was no improvement in steatohepatitis or fibrosis at follow-up. The other two trials did not suggest any improvement in liver enzymes, steatosis, steatohepatitis or fibrosis. The remaining trials performed to date have been observational in design, had small sample size, and have had a short follow-up period. The thiazolidinediones are a class of insulin-sensitizing agents used to treat type II diabetes. Troglitazone was evaluated in an open-label trial involving 10 patients for duration of four to six months (29). These patients had improvement in transaminases and liver histology. However, this medication was subsequently withdrawn from the market due to serious hepatic toxicity. Both rosiglitazone (30) and pioglitazone (31) have been studied in open-label design, and have shown improvement in transaminases, steatosis and fibrosis. Recently VSL\#3 was shown to lower markers of lipid peroxidation in patients with NASH (32). However, larger randomized studies are needed before routine recommendation of these agents in the treatment of NASH.

\section{Bariatric surgery}

Historically, there have been reduced prevalence and severity of liver disease after bariatric surgery. However, in some of these studies, there has been progression of liver disease in patients postoperatively. In the early age of bariatric surgery, jejunoileal bypass was the procedure most commonly performed. A substantial proportion of patients developed advanced liver disease, presumably from bacterial overgrowth and endotoxemia in the bypassed intestine, resulting in bacterial translocation and liver disease. However, the jejunoileal bypass surgery has seldom been performed in recent years due to the multiple complications arising from this procedure. A recent meta-analysis suggested that surgical therapy for weight loss was superior to other methods of weight loss in patients with BMI greater than $40 \mathrm{~kg} / \mathrm{m}^{2}$ (33). This weight loss was sustained for a 10-year follow-up. Although there was a trend toward improved weight loss in patients with BMI between $35 \mathrm{~kg} / \mathrm{m}^{2}$ and $39 \mathrm{~kg} / \mathrm{m}^{2}$ in the surgically treated group, the data cannot be considered conclusive. Recently, one study evaluated laparascopic surgical weight loss via one of three techniques: roux-en-Y gastric bypass, laparascopic adjustable gastric band and sleeve gastrectomy in patients with established NAFLD and metabolic syndrome. Mean BMI was $56 \mathrm{~kg} / \mathrm{m}^{2}$ (34). Patients had liver biopsies at the time of the bariatric surgery followed by a repeat biopsy after 15 months. Mean excess weight loss at the time of the second biopsy was 59\%. There was a marked improvement in live steatosis, steatohepatitis and fibrosis. In fact, in some patients, inflammation and fibrosis completely resolved. Additionally, there was improvement in the metabolic risk factor profile. Hence, as newer methods of bariatric surgery become more popular, there may be a future role for this type of surgery in morbidly obese patients with NASH.

\section{Role of liver biopsy}

Often, NAFLD is a diagnosis of exclusion. Patients are given advice regarding lifestyle modifications and re-evaluated clinically and biochemically several months later in routine follow-up. This may be a reasonable approach for the time being because there are no effective medications in the treatment of NAFLD. However, as pharmacotherapy becomes an option in the future, this line of thought may need to be revised. The distinction between pure fatty change and steatohepatitis can only be made histologically. This distinction is important because NAFLD has a benign prognosis, whereas NASH progresses toward cirrhosis. Because of the risk of NASH in patients suspected to have fatty liver, it could be argued that all patients should be offered a liver biopsy to stage the disease. However, in terms of logistics, cost and side effects, this may not be possible. Hence, it is reasonable to biopsy patients with risk factors for more advanced disease such as advancing age, obesity, hypertension and diabetes mellitus. Additionally, the liver biopsy may occasionally reveal unsuspected abnormalities indicating an alternate or additional diagnosis to fatty liver.

\section{CONCLUSIONS}

As the obesity epidemic continues to grow, the incidence and prevalence of NAFLD will increase as well. The primary abnormality appears to be that of intrinsic insulin resistance. The natural history of NAFLD is quite variable, ranging from benign disease to decompensated disease resulting in ascites, variceal bleeding, hepatocellular carcinoma or death. Currently, no pharmacological therapies are approved for the treatment of NASH. The mainstay of treatment continues to be weight loss therapy through diet and exercise, and aggressive risk factor control. Although some drugs appear to be favourable in pilot studies in the treatment of NASH, further randomized controlled studies are needed before routine recommendations of these agents. 


\section{REFERENCES}

1. Ludwig J, Viggiano TR, McGill DB, Ott BJ. Nonalcoholic steatohepatitis. Mayo Clin Proc 1980;55:434-8.

2. Mezey E. Dietary fat and alcoholic liver disease. Hepatology 1998;28:901-5.

3. Bellantani S, Saccoccio G, Masutti F, et al. Prevalence of and risk factors for hepatic steatosis in northern Italy. Ann Intern Med 2000;132:112-7.

4. Gupte P, Amarapurkar D, Agal S, et al. Nonalcoholic steatohepatitis in type 2 diabetes mellitus. J Gastroenterol Hepatol 2004;19:854-8.

5. Lee JH, Rhee PL, Lee JK, et al. Role of hyperinsulinemia and glucose intolerance in the pathogenesis of nonalcoholic fatty liver in patients with normal body weight. Korean J Intern Med 1998;13:12-4.

6. Adams L, Lymp J, Sauver J, et al. The natural history of nonalcoholic fatty liver disease: A population-based cohort study. Gastroenterology 2005;129:113-21.

7. Caldwell SH, Oelsner DH, Iezzoni JC, Hespenheide EE, Battle EH, Driscoll CJ. Cryptogenic cirrhosis: Clinical characterization and risk factors for underlying disease. Hepatology 1999;29:664-9.

8. Bacon BR, Farahvash MJ, Janney CG, Neuschwander-Tetri BA. Nonalcoholic steatohepatitis: An expanded clinical entity. Gastroenterology 1994;107:1103-9.

9. Saadeh S, Younossi ZM, Remer EM, et al. The utility of radiological imaging in nonalcoholic fatty liver disease. Gastroenterology 2002;123:745-50.

10. Brunt EM, Janney CJ, Di Bisceglie AM, Neuschwander-Tetri BA, Bacon BR. Nonalcoholic steatohepatitis : A proposal for grading and staging the histology lesions. Am J Gastroenterol 1999;94:2467-74.

11. Marchesni G, Brizi M, Bianchi G, et al. Nonalcoholic fatty liver disease: A feature of the metabolic syndrome. Diabetes 2001;50:1844-50.

12. Angelico F, Del Ben M, Conti R, et al. Insulin resistance, the metabolic syndrome and nonalcoholic fatty liver disease. J Clin Endocrinol Metab 2005;90:1578-82.

13. Scheen AJ, Luyckx FH. Obesity and liver disease. Best Pract Res Clin Endocrinol Metab 2002;16:703-6.

14. Harrison SA, Kadakia S, Lang KA, Schenker S. Nonalcoholic steatohepatitis: What we know in the new millennium. Am J Gastroenterol 2002;97:2714-24.

15. Festi D, Colecchia A, Sacco T, Bondi M, Roda E, Marchesini G. Hepatic steatosis in obese patients: Clinical aspects and prognostic significance. Obes Rev 2004;5:27-42.

16. Kejima K, Okumura K, Lang T, et al. The role of leptin in progression of nonalcoholic fatty liver disease. Hepatol Res 2005;33:151-154.

17. Sargin H, Sargin M, Gozu H, et al. Is adiponectin level a predictor of nonalcoholic fatty liver disease in nondiabetic male patients? World J Gastroenterol. 2005;11:5874-7.

18. Chitturi S, Farrell GC. Etiopathogenesis of nonalcoholic steatohepatitis. Semin Liver Dis 2001;21:27-41.

19. Yeon J, Choi K, Baik S, et al. Reduced expression of peroxisome proliferators-activated receptor alpha may have an important role in the development of nonalcoholic fatty liver disease. J Gastr Hep 2004;19:799-804.

20. Sanyal AJ, Campbell-Sargent C, Mirshahi F, et al. Nonalcoholic steatohepatitis: Association of insulin resistance and mitochondrial abnormalities. Gastroenterology 2001;120:1281-5.
21. Cox KL, Burke V, Morton AR, Beilin LJ, Puddey IB. Independent and additive effects of energy restriction and exercise on glucose and insulin concentrations in sedentary overweight men. Am J Clin Nutr 2004;80:308-16.

22. Angulo P. Current best treatment for nonalcoholic fatty liver disease. Expert opin Pharmacother 2003;4:611-23.

23. Dansinger M, Gleason J, Griggith J, Selker H, Schaefer E. Comparison of the Atkins, Ornish, Weight Watchers, and Zone diets for weight loss and heart disease risk reduction. JAMA 2005;93:43-53.

24. Harrison S, Ramrakhiani S, Brunt E, Anbari M, Cortese C, Bacon B. Orlistat in the treatment of NASH: A case series. Am J Gastroenterol 2003; 98:926-30.

25. Davidson MH, Hauptman J, DiGirolamo M, et al. Weight control and risk factor reduction in obese subjects treated for 2 years with orlistat: A randomized controlled trial. JAMA 1999;281:235-42.

26. Sabuncu T, Nazligul Y, Karaoglanoglu M, et al. The effects of sibutramine and orlistat on the ultrasonographic findings, insulin resistance and liver enzyme levels in obese patients with nonalcoholic steatohepatitis. Rom J Gastroenterol 2003;12:189-92.

27. Despres JP, Golay A, Sjostrom L et al. Effects of rimonabant on metabolic risk factors in overweight patients with dyslipidemia. N Engl J Med 2005;353:2121-34.

28. Centers for Disease Control and Prevention. Physical activity for everyone: Recommendations: How active do adults need to be to gain some benefit?

29. Caldwell SH, Hespenheide EE, Reddick JA, Iezzoni JC, Battle EH, Sheppard BL. A pilot study of a thiazolidinedione, troglitazone, in nonalcoholic steatohepatitis. Am J Gastroenterol 2001;96:519-25.

30. Neuschwander-Tetri BA, Brunt EM, Wehmeier KR, Oliver D, Bacon BR. Improved nonalcoholic steatohepatitis after 48 weeks of treatment with the PPAR-gamma ligand rosiglitazone. Hepatology 2003;38:1008-17.

31. Promrat K, Lutchman G, Uwaifo GI, et al. A pilot study of pioglitazone treatment for nonalcoholic steatohepatitis. Hepatology 2004;39:188-96.

32. Loguercico C, Federico A, Tuccillo, C, et al. Benefical effects of a probiotic VSL\#3 on parameters of liver dysfunction in chronic liver diseases. J Clin Gastroenterol 2005;39:540-3.

33. Maggard MA, Shugarman LR, Suttorp M et al. Meta-analysis: Surgical treatment of obesity. Ann Intern Med 2005;142:547-59.

34. Mattar S, Velcu L, Rabinovitz M. Et al. Surgically-induced weight loss significantly improves nonalcoholic fatty liver disease and the metabolic syndrome. Ann Surg 2005;242:610-7.

35. Uygun A, Kadayifci A, Isik AT, et al. Metformin in the treatment of patients with nonalcoholic steatohepatitis. Aliment Pharma Ther 2004; 19:537-44.

36. Lindor KD, Kowdley KV, Hethcote EJ, et al. Ursodeoxycholic acid for treatment of nonalcoholic steatohepatitis: Results of a randomized trial. Hepatology 2004;39:770-8.

37. Harrison SA, Torgerson S, Hayashi P, Ward J, Schenker S. Vitamin E and vitamin $\mathrm{C}$ treatment improves fibrosis in patients with nonalcoholic steatohepatitis. Am J Gastroenterol 2003;98:2485-90.

38. Abdelmalek M, Angulo P, Jorgensen RA et al. Betaine, a promising new agent for patients with nonalcoholic steatohepatitis: Results of a pilot study. Am J Gastroenterol 2001;96:2711-7. 


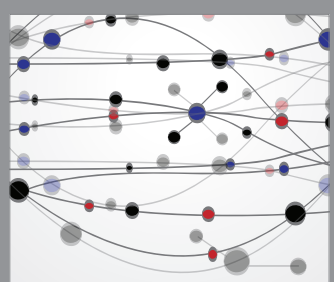

The Scientific World Journal
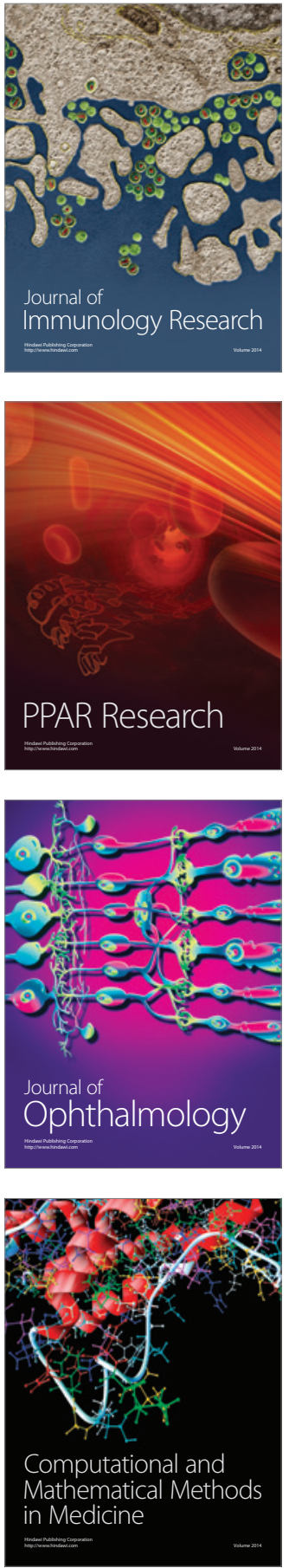

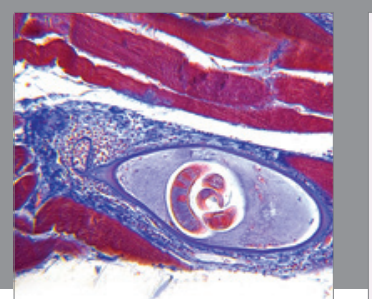

Gastroenterology Research and Practice

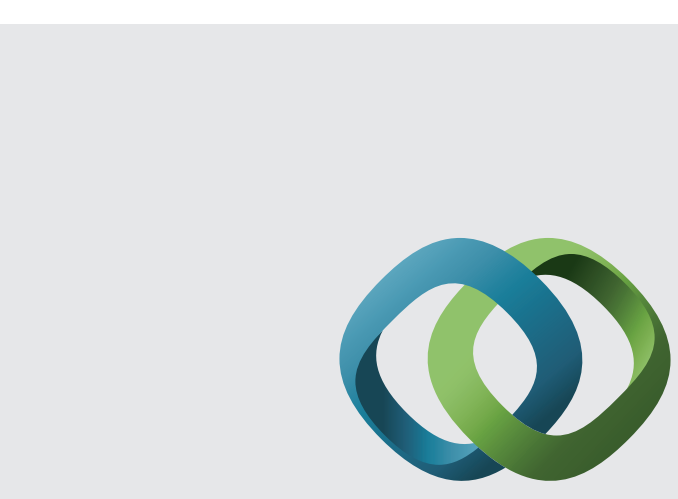

\section{Hindawi}

Submit your manuscripts at

http://www.hindawi.com
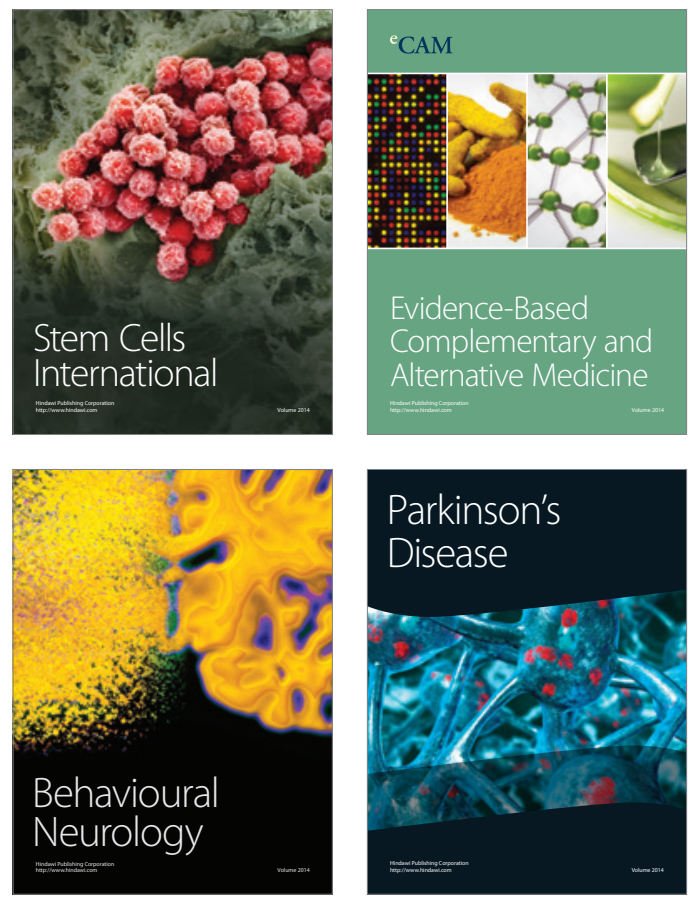
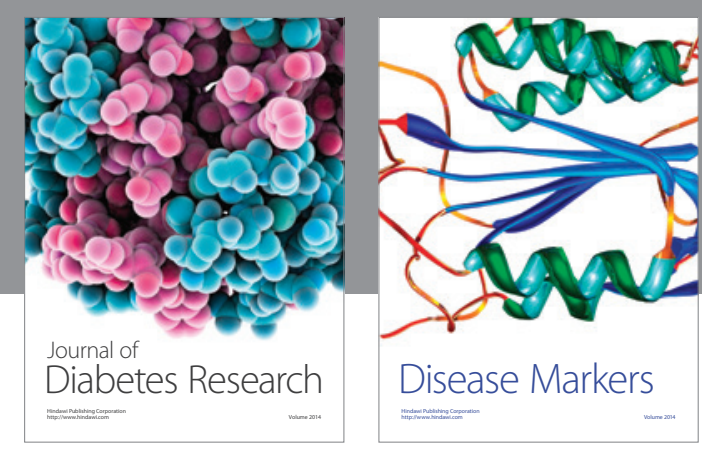

Disease Markers
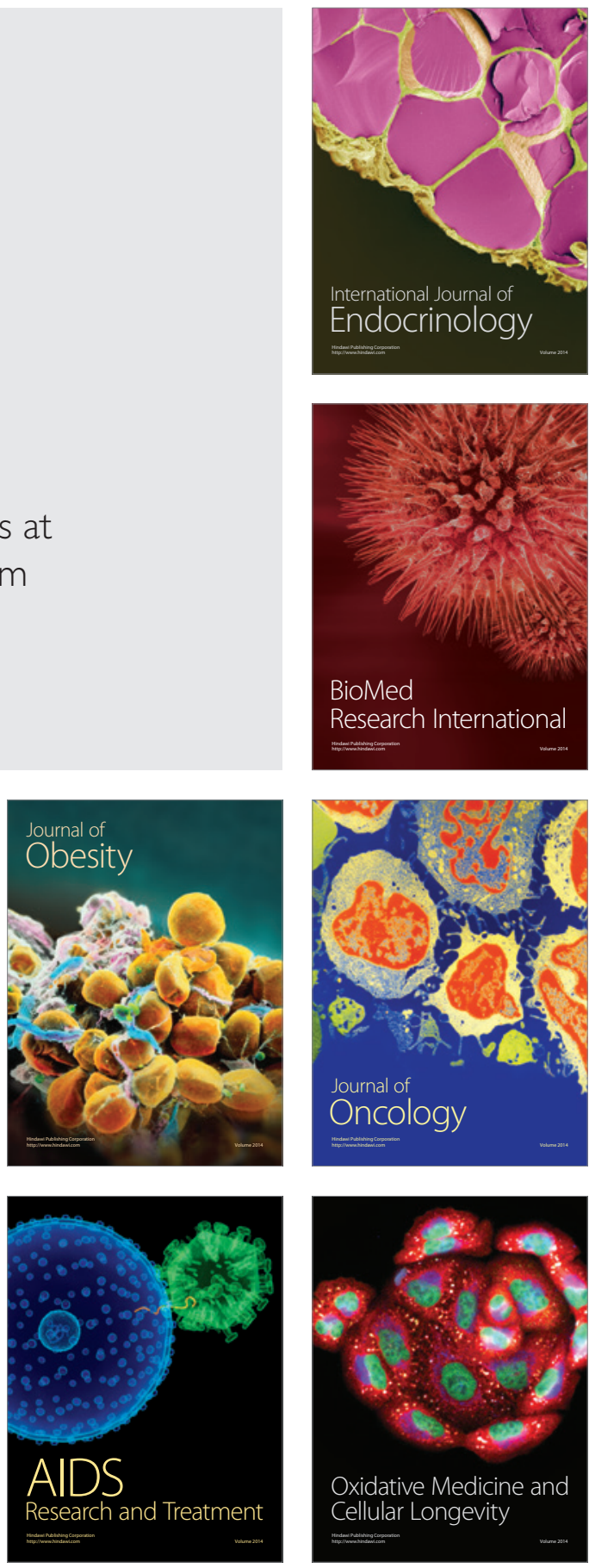